\title{
SOB OS OLHOS DE KUNUMIM: A LITERATURA INDÍGENA BRASILEIRA NO CÍRCULO LITERÁRIO INFANTOJUVENIL
}

Lívia Penedo Jacob (UERJ)

Resumo: No presente artigo, analisamos como a literatura indígena brasileira tem sido continuamente associada à literatura infantojuvenil. A partir do estudo de diversas obras ameríndias, são levantadas múltiplas questões pertinentes ao tema, inclusive no que tange à própria noção de gênero literário, comumente aplicado nos estudos teóricos da área sem grandes reflexões sobre a sua aceitação pelas culturas não ocidentais. Outras características marcadamente presentes nessas publicações são discutidas, tais como as ilustrações e uma temática notável por sua recorrência nessas obras, aqui denominada "metamorfoses ameríndias". Trata-se de personagens transmorfos, isto é, sujeitos que se metamorfoseiam em animais ou vice-versa. Propomos, por fim, a leitura contextualmente guiada como um caminho mais seguro para a adoção das mesmas em sala de aula.

Palavras-chave: Literatura Indígena; Literatura Infantojuvenil; Colonização.

Abstract: In the present article, I analyze how Brazilian indigenous literature has been continuously associated with children's and youth literature. From the analysis of several Amerindian books, some relevant questions appeared, including the notion of literary genre, commonly applied in theoretical studies in the area without major reflections on its acceptance by non-Western cultures. Other features commonly present in these literatures are discussed, such as illustrations and one theme, notable for its recurrence, that I call "Amerindian metamorphoses", applied to transformers or tricksters. My aim is to understand a culturally contextualized reading as a educational method to better understand these works.

Keywords: Indigenous literature; Children's literature; Colonization. 
Sabemos que a literatura dedicada ao público juvenil tem seu surgimento atrelado à ascensão da classe burguesa. Durante a Revolução Industrial, a família passa a desempenhar um papel central na sociedade, surgindo, enfim, a ideia de que a criança não é tão somente um adulto miniaturizado, e sim um sujeito com direitos e deveres. Exemplifica essa ideia o conjunto de leis francesas conhecidas como leis Jules Ferry, promulgadas entre os anos de 1881 e 1882, e que garantiam educação gratuita e laica a todos os cidadãos dos 6 aos 13 anos de idade. Na mesma época, surgiram diversas outras áreas relacionadas à infância, tais como a pedagogia e a pediatria, além das primeiras análises psicanalíticas sobre a sexualidade infantil empreendidas pioneiramente por Freud. Nesse contexto, fica claro que a literatura infantil esteve, em seus primórdios, vinculada a um projeto educacional e ao próprio surgimento da escola como instituição social.

Esse atrelamento da literatura infantojuvenil à educação dos jovens e das crianças persiste até os dias de hoje, em que não raramente os autores de livros dedicados a esse público são também professores. A esse respeito, citamos Riita Oittinen, para quem “a pedagogia sempre desempenhou um importante papel em tudo o que é criado 
(por adultos) para crianças"11 (2000, p.43 - tradução nossa). Ou seja, a teoria que versa sobre as obras infantis assume que a escrita direcionada ao público jovem se presta não apenas ao entretenimento, mas também a ideais educativos. Ora, a literatura infantojuvenil brasileira também desde os seus primórdios se desenvolveu no sentido de afirmar esse valor. Não à toa as obras de seu pioneiro, Monteiro Lobato, foram, por muitos anos, adotadas como livros obrigatórios nas escolas, realidade que recentemente mudou devido a polêmicas envolvendo acusações de racismo em suas obras. Após décadas de "reinações", Lobato passou a ser contestado em sua hegemonia, deixando de ser uma "unanimidade"; contudo, figura ainda em uma espécie de "cânone" do gênero, ao lado de Ruth Rocha, Pedro Bandeira, Lygia Bojunga, Ziraldo, Sylvia Orthof, entre outros nomes.

Em suma, vemos que a literatura infantojuvenil segue, no Brasil e no exterior, sendo majoritariamente encarada como um instrumento de apoio pedagógico. Nesse caso, a escolha é hierarquizada, isso quando há escolha: em geral, um adulto (pais ou professores) decide, primeiramente, o que a criança deve ler com base naquilo que crê ser mais instrutivo. Ou seja, o leitor é, raras vezes, consultado sobre as suas preferências,

\footnotetext{
1 No original: "Pedagogy has always played an important part in anything created (by grownups) to children".
} 
tornando-se passivo, dentro e fora da escola. Assim, embora o sistema educacional tenha se reconfigurado ao longo dos séculos, pelo menos no que diz respeito ao ensino da literatura não houve um descolamento completo da ideologia burguesa do século XIX. Por isso mesmo, o patrulhamento público em cima de obras desse gênero ainda é constante, e não raras vezes ressurge algum debate público sobre livros ou histórias em quadrinho que devem ser "banidos" por constituírem uma ameaça aos jovens. Afinal, a ideologia burguesa, como se sabe, é conservadora e excludente, não se interessando em escutar as necessidades do que reside à margem. Cabe, então, tentarmos entender qual o espaço, dentro da realidade acima descrita, para as literaturas ditas "periféricas" produzidas para crianças?

Não podendo investigar amplamente o assunto, nos concentraremos em abordar a literatura de autoria indígena e sua recepção no universo infantil. Conquanto tenha surgimento anterior em outros países da América, no Brasil essa produção é ainda relativamente recente, sendo considerado o primeiro livro indígena Antes o mundo não existia, publicado em 1980 pelos desanas Umusi Parõkumu e Tõramu Kehíri. Somente na década posterior diversas outras obras começariam a ser publicadas por autores oriundos 
de outras etnias. No cenário infantojuvenil, destaca-se o escritor Daniel Munduruku, já laureado com diferentes prêmios, dentre eles o Jabuti, o mais tradicional prêmio literário nacional. Refletindo sobre sua própria produção em O caráter educativo do movimento indígena brasileiro (1970 - 1990), o autor argumenta que o indígena, para além de seu caráter político, esteve permeado também de roupagem pedagógica, objetivando não somente a construção de uma nova visão de mundo para os ameríndios, mas também para a sociedade brasileira como um todo:

Talvez a maior contribuição que o movimento indígena ofereceu à sociedade brasileira foi o de revelar - e, portanto, denunciar a existência da diversidade cultural e linguística. $\mathrm{O}$ que antes era visto somente como uma presença genérica passou a ser encarado como um fato real, obrigando a política oficial a reconhecer os diversos povos como experiências coletivas e como frontalmente diferentes da concepção de unidade nacional.

(MUNDURUKU, 2012, p.222)

Nesse livro teórico, fruto da tese de doutoramento de Daniel Munduruku, o pesquisador e escritor, que é educador por formação, assume que sua literatura está fortemente ligada à educação de jovens e crianças não indígenas, como meio de pacificação das futuras gerações e instrução sobre 
a importância das culturas ameríndias. Essa concepção é reafirmada pelo autor em diversas outras obras, artigos e entrevistas. Em sua autobiografia Memórias de Índio, por exemplo, ele diz que vê a literatura como um "instrumento pedagógico [...] comprometida com a transformação social" (MUNDURUKU, 2016, p.177). Também no compêndio Literatura indígena brasileira contemporânea, Daniel Munduruku mais uma vez enfatiza esse posicionamento: “O papel da literatura indígena é, portanto, ser portadora da boa notícia do (re)encontro" (DORRICO et al., 2018, p.83). 0 citado volume traz ainda diversos textos de outros autores indígenas brasileiros concordantes em declarar o valor político de suas produções, tal como o faz Márcia Kambeba: "[a literatura indígena] nos dá possibilidades para que, fora da aldeia, alunos e pessoas possam se aprofundar em determinado assunto ou mesmo saber como cada povo vive, resiste e defende seu território" (DORRICO et al., 2018, p.40).

Ora, a ideia de que a literatura deva ter um objetivo - seja ele político ou educativo ou ambos - contrasta fortemente com a postura comumente adotada pela maioria dos autores canônicos de teoria da literatura, para os quais o vínculo entre a literatura e o ensino deve ser rechaçado, no sentido de que os romances, biografias, poemas e outras produções 
não podem ser delimitadas por qualquer tipo de objetivo doutrinário específico. Para Lajolo e Zimberman (2007, p.12), por estar "sob a chancela de instituições sociais como a escola", o estudo desse tipo de literatura "cria problemas sérios para o teórico e o historiador que dela se aproximam munidos dos instrumentos consagrados pela história e pela teoria literária". Assim, a literatura infantojuvenil, segundo seus estudiosos, carece ainda de independência acadêmica, devendo se direcionar rumo à construção de um campo teórico próprio. Sem intenção de abordar essa problemática com profundidade, concordamos, porém, que a produção literária dedicada aos jovens e crianças possui arsenal suficiente para se solidificar como um campo de saber autônomo. Nesse sentido, será interessante que seus teóricos questionem os parâmetros classificatórios utilizados hoje para determinar o que venha a ser a literatura infantojuvenil e de que forma esses critérios se estendem ou não às produções oriundas de outras culturas.

É que, apesar desse aparente contentamento dos autores indígenas com a literatura infantojuvenil enquanto meio possível para educar as crianças não indígenas sobre suas realidades, a classificação dessas literaturas em um gênero literário ocidental não nos parece adequada. Afinal, 
analisando a produção indígena em geral, observamos que os critérios de classificação atualmente empregados são escorregadios. Por exemplo, os livros Lua menina e menino onça, de Lia Minápoty (2015), e A mulher que virou urutau, de Olívio Jekupe e Maria Kerexu (2011) contêm somente uma fábula conectada à cultura indígena dos povos aos quais os narradores pertencem e assemelham-se, ainda, por apresentarem desenhos marcantes e estrutura gráfica característica das edições infantis nacionais, tais como papel couchê e paginação diferenciada $(25 \mathrm{~cm} \times 21 \mathrm{~cm})$. Contudo, enquanto o primeiro foi classificado como literatura infantil, o segundo possui ISBN correspondente a ficção brasileira.

Essa oscilação técnica na catalogação dos livros indígenas nos leva a crer que as obras indígenas pertencem a gênero fluido, tendo em vista que as referidas culturas estão fortemente marcadas pela importância da coletividade, não havendo segregação social dos componentes humanos a partir de faixas etárias. Desse modo, pensar em uma literatura indígena dedicada exclusivamente a um público infantil seria um contrassenso, visto que nas aldeias as atividades são realizadas em conjunto, inclusive a contação de histórias. Por outro lado, condicionar as narrativas dos povos tradicionais a gêneros literários específicos não parece funcionar, uma 
vez que os autores desses textos possuem percepções particulares sobre o que venha a ser ficção. Assim, em muitos textos indígenas brasileiros observamos uma fusão entre mitos e sonhos, e as histórias podem trazer informações importantes sobre a descrição de plantas, animais e até de remédios. Uma narrativa saterê-mawé, por exemplo, explica como o guaraná brotou dos olhos do filho de Onhiámuáçabe. Longe de comportar mera "história da carochinha", esse conto educa o leitor sobre as características da planta guaraná, deixando claro que arte, nesses casos, pode estar vinculada a uma "utilidade" pedagógica, mnemônica ou científica. A inserção das obras indígenas junto ao gênero infantil se explicaria, portanto, mais pelas diferenças culturais envolvidas na produção das obras do que por uma intenção real dos autores de condicioná-las a um único público. Ou seja, aos olhos do leitor não indígena diversos livros indígenas são infantojuvenis. Essa interpretação tem como base o escasso conhecimento de mundo não ocidental dos leitores que acessam essas obras.

A ignorância sobre as culturas indígenas é uma pista que nos auxilia a entender melhor a associação entre literatura indígena e literatura infantil no imaginário social brasileiro. A literatura indígena estaria afinada com as expectativas que 
a sociedade não indígena sobre a literatura infantojuvenil: uma literatura em geral considerada "menor" ou "menos relevante" pela crítica, criada com base na oralidade porque imaginada para ser lida em voz alta e rigidamente relacionada com os projetos pedagógicos da sociedade. A respeito do desprezo intelectual pela literatura infantojuvenil como campo de estudo, Peter Hunt assinala que os livros dedicados às crianças não ocupam um espaço de estudos relevantes dentro da academia, mas "essa marginalização apresenta certas vantagens; porque é culturalmente pouco ostensiva, a 'literatura infantil' não se tornou exclusividade de nenhum grupo ou disciplina"2 (HUNT, 2002, p.2 - tradução nossa). Haveria, pois, uma vantagem para os indígenas nesse sentido, porque se veriam livres de campos acadêmicos tradicionais, conhecidamente mais rígidos e menos maleáveis do que a literatura infantil.

Outra associação que poderia levar o leitor ocidental a creditar um teor "jovem" a essas obras reside no fato de que comumente são ilustradas. Muitos autores indígenas que afirmam não produzir obras para crianças se deparam com esse tipo de questionamento. Todas as vezes que dissemos adeus, obra autobiográfica de Kaká Werá Jecupé,

2 No original: "this marginalisation has had certain advantages; because it has been culturally lowprofile, 'children's literature' has not become the 'property' of any group or discipline". 
traz uma série de fotos sobre a temática guarani. Quando questionado a respeito de sua escrita à época da publicação, o autor afirmou, em entrevista (ASSUNÇÃO, 1999), que a escrita indígena existia; ela estava, porém, ligada aos grafismos, às cestarias e às pinturas corporais, traduzindose, assim, por simbolismos. Com essa revelação, Kaká Werá nos dá uma pista sobre como esse processo de adaptação da oralidade para a língua escrita é feita por alguns autores indígenas brasileiros: por meio da inserção de grafismos e de gravuras nas obras literárias. Ou seja, as ilustrações, longe de buscarem exclusivamente uma aproximação com o público infantil, buscam, de fato, traduzir a oralidade intraduzível das narrativas indígenas originais. Essa característica, aliás, se repete em outras sociedades tradicionais marcadas pela ausência de escrita.

A esse respeito, o livro Stories of the Road Allowance People, da indígena métis canadense Maria Campbell, é peculiar. Primeiramente, chama a atenção que Campbell não assuma a autoria da obra, informando, na capa, que o livro foi "traduzido e vertido para a escrita por Maria Campbell". Esse conceito converge com a percepção de que as literaturas orais não possuem autoria clara, sendo o contador de histórias muitas vezes um recontador. 
Além disso, a obra conta com uma série de ilustrações. Quando questionada sobre essas imagens, Campbell afirmou que:

As ilustrações foram (pensadas) para os idosos que me contaram as histórias porque alguns leem e escrevem pouco. Eu queria que eles não apenas segurassem e olhassem o livro sem entendê-lo, mas que fossem capazes de também lê-lo. Os desenhos foram feitos pela Sherry. Eu não disse a ela o que eu queria. Ao contrário, quando terminei de escrever o livro, dei a ela. Para que terminasse de traduzi-lo [...]. O desenho é uma outra forma de tradução ${ }^{3}$. (GINGELL, 2004, p.201 - tradução nossa)

Vê-se, assim, que as narrativas indígenas e de outras sociedades tradicionais, quando versadas para o papel e para uma língua dominante, estão mais próximas do que seria uma tradução transcultural. O conceito de tradução transcultural é um desdobramento da ideia de tradução cultural, inicialmente cunhado por Burke quando defendeu que as traduções empreendidas ao longo da história europeia atendiam "às necessidades, aos interesses, aos preconceitos e às maneiras de ler da cultura-alvo, ou pelo menos de alguns grupos dentro dela" (2009, p.152).

3 No original: The print size was for the elders who gave me the stories because some of them could read and write a little. I wanted them to not just hold the book in their hands and see it but to be able to read it as well. The pictures are Sherry's. I didn't tell her what I wanted. Rather, when I finished the stories, I gave them to her. She had to finish translating them [...]. The artwork is another level of translation. 
$\mathrm{Na}$ tradução transcultural, muitas vezes esse direcionamento pode estar acontecendo, ainda que não intencionalmente, entre sociedades ágrafas e sociedade letradas. De todo modo, a tradução transcultural ocorre quando a tradução literal entre línguas está sendo feita concomitantemente à tradução de culturas que se apoiam em suportes textuais díspares. Os autores buscarão, nesses casos, compensar, de forma criativa, a ausência do corpo físico do narrador e as adaptações variam conforme escolha dos autores. Por exemplo, ao investigarmos textos ameríndios norte-americanos, descobrimos que muitas vezes as marcas de oralidade são enfatizadas por meio do code-switching ${ }^{4}$, segundo revela Kristina Fagan (Apud DEPASQUALE et al., 2010, p.25) quando aponta que a interposição do inglês entre frases no idioma nativo do autor é um recurso estilístico comumente empregado por autores indígenas canadenses com o objetivo de gerar estranhamento no leitor não nativo.

No caso das obras indígenas brasileiras, para além do uso de imagens, observamos que o desconhecimento sobre essas culturas gera interpretações equivocadas sobre as temáticas apresentadas, levando muitos leitores a compreender essas narrativas como "fábulas". Esse problema acontece devido

4 Termo técnico usado pela linguística para se referir à alternância de códigos linguísticos praticada por falantes de mais de uma língua. 
a uma recorrência, nessas obras, daquilo que escolhemos denominar "metamorfoses ameríndias", a saber: a profusão de personagens que se transformam de gente em bicho ou vice-versa. A respeito da literatura norte-americana, os já muito estudos empreendidos a esse respeito denominam essas figuras "tricksters", mas optamos pela palavra "transmorfos", oriunda de nossa língua pátria e, portanto, mais familiar. Dois livros indígenas anteriormente citados neste artigo Lua menina e menino onça, de Lia Minápoty (2015) e $A$ mulher que virou urutau, de Olívio Jekupe e Maria Kerexu (2011), apresentam transmorfos. No primeiro caso, narra-se a história de um kunumin que se transforma em onça. Por seu poder, ele é alijado de sua aldeia, sendo obrigado a viver sozinho entre praias e florestas. Graças à sua fé e sua adoração pela Lua, ela o ajuda todas as noites, descendo à Terra e, por fim, casando-se com ele. Em A mulher que virou urutau, uma bela moça é pedida em casamento pelo Lua, que se apresenta como um homem velho, porém apaixonado. Ela se recusa a ceder, e acaba transformada em um estranho pássaro noturno, o urutau, cujo canto sinistro lembra um lamento.

Nos dois casos, fala-se de mitos, tabus e tradições tribais pouco intuitivas para aqueles que não pertencem a essas comunidades. Os transmorfos estão presentes: a lua se 
metamorfoseia em gente e as pessoas também podem se transformar em elementos da natureza. Observamos esse fenômeno em diversas outras narrativas indígenas, dentre as quais citamos as encontradas em Contos da floresta, de Yaguarê Yamã, da etnia amazônica saterê-mawé (vulgo maué ou maraguá). O livro de Yaguarê traz histórias tradicionais recontadas pelo autor à sua maneira, muitas das quais falam de criaturas fantásticas, híbridos entre o humano e o sobrenatural. No conto "História de Kãwera" deparamo-nos com a personagem referida no título, segundo o autor um "[...] esqueleto velho. Ser da mitologia maraguá, metade homem, metade morcego" (YAMÃ, 2012, p.56). Nas narrativas, as personagens indígenas geralmente são surpreendidas por essas criaturas tétricas quando estão caçando e, portanto, se encontram sozinhos na mata em situação de vulnerabilidade. Veja-se o exemplo abaixo:

Mas, rapidamente, sentiu sua cabeça crescer e os cabelos se arrepiarem, ao ver descer à sua frente um terrível monstro alado, de asas de morcego. Ao pousar, deixou à mostra dentes enormes e garras, com as quais arranhou o homem nas costas. Em seguida, o monstro levantou vôo e sumiu na escuridão da mata. (YAMÃ, 2012, p.13)

Outras figuras grotescas fazem suas aparições nos contos de Yamã. Citamos "As Makukáwas" e "História de 
Mapinguary". Na primeira narrativa, um homem com pés de pássaro aparece para amedontrar uma mulher que reclama por ter que depenar a caça da tribo. Já o Mapinguary é uma entidade sobrenatural personificada em uma figura humanoide "com o corpo coberto de pelos e boca no estômago" (YAMÃ, 2012, p.56), que atrai pessoas com pedaços de carne para, na realidade, devorá-las. No entanto, a ardilosa criatura devora tão somente o corpo das vítimas, deixando de lado as cabeças, que se transformam em outros mapinguaris: "Tomou um susto, ao ver que o corpo do amigo não estava mais lá, apenas a cabeça. O homem parou. E, no momento em que se virou, viu a cabeça se transformando em Mapinguary" (2012, p.30).

Para entender as possíveis explicações culturais para esses personagens transmorfos, buscamos explicação nos estudos antropológicos sobre o tema. Nesse sentido, os estudos empreendidos por Eduardo Viveiros de Castro lançam luz à problemática. Em seus estudos, o autor percebeu essa maleabilidade entre entidades humanas e não humanas e visíveis e invisíveis quando estudou a cosmogonia e o dia a dia dos povos ameríndios da Amazônia. Para o pesquisador, os papéis individuais e sociais dos membros das comunidades com as quais conviveu muitas vezes também 
se caracterizam por não serem entidades fixas, isto é, os status variam conforme as passagens de rituais, a captura de inimigos, o destaque na manipulação de ervas, dentre outras situações culturais específicas. Com base no estudo de diversos outros autores e de sua própria vivência entre esses povos, Viveiros de Castro explica como essas relações de constante transformação social, nas quais os papéis e histórias de cada sujeito são mutáveis, encontra paralelo na filosofia ameríndia. Em suas conclusões, o antropólogo mostra que mesmo elementos naturais supostamente inanimados (pedras, árvores, rios), podem estar sob suspeita aos olhos das tradições amazônicas, fenômeno que nomeou como "perspectivismo ameríndio", ou, mais recentemente, "multiculturalismo". Segundo essa proposta, a cosmogonia estudada defende que a forma externa de cada animal pode ser uma roupa que esconde uma forma interna humana, não perceptível para todos:

Tipicamente, os humanos, em condições normais, veem os humanos como humanos e os animais como animais; quanto aos espíritos, ver estes seres usualmente invisíveis é um signo seguro de que as 'condições' não são normais. Os animais predadores e os espíritos, entretanto, veem os humanos como animais de presa, ao passo que os animais de presa veem os humanos como espíritos ou como animais predadores: 
"O ser humano se vê a si mesmo como tal. A lua, a serpente, o jaguar e a mãe da varíola o veem, contudo, como um tapir ou um pecari, que eles matam", anota Baer (1994, p. 224) sobre os Matsiguenga. Vendo-nos como não-humanos, é a si mesmos que os animais e espíritos veem como humanos.

(CASTRO, 2016, p.350)

Conforme conclusão desses estudos, o curandeiro é a figura dentro do grupo com poderes sobrenaturais, capaz de curar e muitas vezes de se metamorfosear, através da interferência de seres sobrenaturais. Muitos desses rituais de cura ou de "passagem" são marcados por metamorfoses, pinturas corporais ou até esfolamentos que, por vezes, se aproximam de uma literal "mudança de pele". Embora tais práticas possam nos parecer incompreensíveis e bárbaras, elas são reveladoras da perfeita adaptação dessas sociedades a ambientes muitas vezes inóspitos e árduos.

No que tange ao enredo dos contos indígenas aqui estudados, importa, por fim, enfatizar que esses transmorfos nada têm a ver com a prosopopeia costumeiramente observada em obras literárias infantojuvenis ocidentais. Conforme nos revelam os estudos antropológicos em pauta, esses povos possuem uma compreensão cíclica do processo existencial: a vida nasce, cresce, se multiplica, morre e renasce. Por outro lado, são culturas que não 
hierarquizam a natureza e para as quais homens, animais, estrelas, pedras e todos os outros elementos do planeta são parte de um todo. Segundo alguns desses povos, os animais são ancestrais espirituais das tribos, dignos, portanto, de devoção e respeito. Assim, vemos que narrativas indígenas estão impregnadas dessa visão mística, e diferente do que ocorre nas fábulas europeias, não existe propriamente uma moral implícita.

Retomemos, pois, a questão inicial deste artigo. Se os contos indígenas não possuem necessariamente uma "moral da história", tal qual se compreende no ocidente, e, ainda, se estão constituídos sobre bases culturais distintas às nossas, podem servir a propósitos pedagógicos, tal como defendido por Daniel Munduruku e outros autores nativos? Ora, o fato de esta literatura não ter sido criada exclusivamente para crianças não impede que seja lida por e para diversas faixas etárias. A problemática que envolve a definição do que venha a ser literatura para crianças, aliás, se estende também às produções ocidentais. Em The case of Peter Pan, Jacqueline S. Rose defende que a literatura infantojuvenil é por si só uma impossibilidade, já que "constrói um mundo no qual o adulto vem primeiro (escritor, produtor, concessor) e a criança depois (leitor, produto, receptor)" ${ }^{5}$ (ROSE, 1998,

5 No original: “Children's fiction sets up a world in which the adult comes first (author, maker, 
p.58 - tradução nossa). Sem qualquer intenção de diminuir a polêmica levantada por Rose, defendemos que a literatura, como outras expressões de arte, é um direito das crianças e adolescentes. E não há dúvidas de que algumas obras comunicam mais ao universo infantojuvenil do que outras. Ainda que Peter Pan e Alice no país das maravilhas venham sendo atualmente lidas como obras que extrapolam a literatura infantojuvenil, é indubitável que despertem mais o interesse dos pequenos do que obras clássicas como Hamlet ou Anna Karenina, por exemplo.

É notório que vários livros produzidos por autores indígenas brasileiros têm sido amplamente aprovados pelos jovens leitores, o que se verifica pela reação desse público em eventos de leitura do gênero. Por outro lado, vale lembrar que a criação da Lei no11.645/2008, em complementação à Lei de Diretrizes e Bases da Educação, Lei no 9.394/1996, ao tornar obrigatório o ensino das contribuições de matrizes africanas e indígenas no ensino básico, se mostrou um grande estímulo para a produção de novos livros, bem como afirmação de autores indígenas interessados em falar para o público jovem. Essa abertura proporcionada pela lei se coaduna com o ideal indígena de comunicar seus interesses e dirimir o preconceito de séculos através de seus textos e giver) and the child comes after (reader, product, receiver)". 
militância. Nesse sentido, a literatura indígena, quando fala para as novas gerações, pretende descolonizar e retirar o indígena da subalternidade imposta por vários séculos.

Os esforços empreendidos pelos indígenas nesse sentido são louváveis e vêm rendendo frutos. Segundo dados disponibilizados pelo INEP - Censo da Educação Superior do Instituto Nacional de Estudos e Pesquisas Educacionais Anísio Teixeira - referentes ao período entre 2010 e 2016, o número de alunos indígenas no ensino superior aumentou mais de 50\% (BRASIL, 2018). A literatura indígena, quando bem utilizada em sala de aula pode, sem dúvida, auxiliar na instrução dos alunos não indígenas quanto às culturas dos povos tradicionais. Contudo, nosso estudo pretende alertar que sozinha a literatura não serve como instrumental para essa finalidade. É preciso instruir primeiramente os professores, bem como pensar em uma educação continuada a respeito deste tema e que preferencialmente aborde os assuntos referentes a essas culturas de maneira transversal.

Nossa análise sobre as idiossincrasias presentes nessas narrativas buscou mostrar que tanto as ilustrações como as temáticas presentes nas obras indígenas possuem significados próprios em conformidade com crenças e costumes desses povos. No que diz respeito às metamorfoses, não devem 
ser confundidas com devaneios ou "contos de fadas". Dentro das culturas em questão, a ficção e a realidade não são tão fronteirizadas, por isso associamos a origem dessas narrativas à própria ontologia desses povos. De todo modo, a leitura dessas narrativas, sem um conhecimento prévio das culturas que as produzem, pode levar o leitor desavisado a compreensões equivocadas. Não é desejável, portanto, que as histórias indígenas subitamente se tornem "apropriadas" para as crianças não indígenas, sem que haja uma preocupação real por parte da escola em conhecer mais profundamente a cultura sobre a qual se está supostamente ensinando, pois corre-se o risco, nesse caso, de que novas fantasias e estereótipos sobre os indígenas sejam criados.

\section{REFERÊNCIAS}

ASSUNÇÃO, Ademir (1999). "Para o escritor Kaká Jecupe, a semente do distanciamento entre brancos e índios está na estrutura das sociedades: uma cultua o ter e a outra o ser". Revista Isto É. Edição 1555. In https://istoe. com.br/32803_500+ANOS+DE+DESENCONTROS Acesso em 1.Fev.2020. BRASIL. Ministério da Justiça (2018). "Estudantes indígenas ganham as universidades". Portal do Ministério da Justiça e Segurança Pública. In https://www.justica.gov.br/news/estudantes-indigenas-ganham-asuniversidades Acesso em 2.Fev.2020.

BURKE, Peter; HSIA, Ronnie Po-chia (Orgs) (2009). A Tradução cultural: nos primórdios da Europa Moderna. Roger Maioli dos Santos (Trad.). São Paulo: Unesp.

CASTRO, Eduardo Batalha Viveiros de (2016). A Inconstância da alma selvagem. São Paulo: Cosac Naif. 
DEPASQUALE, Paul; EIGENBROD, Renate; LAROQUE, Emma (2010). Across cultures, across borders - Canadian Aboriginal and Native literatures. Peterborough: Broadview Press.

DORRICO, Julie; DANNER, Leno Francisco; CORREIA, Heloisa Helena; DANNER, Fernando (Orgs.) (2018). Literatura indígena brasileira contemporânea: criação, crítica e recepção. Porto Alegre: Editora Fi.

GINGELL, Susan (2004). "One Small Medicine: An Interview with Maria Campbell". Essays on Canadian Writing, 83, Fall, 188-205.

HUNT, Peter (Ed.) (2002). Understanding children literature. Taylor and Francis e-Library.

JEKUPE, Olívio; KEREXU, Maria (2011). A Mulher que virou urutau: Kunha urutau reojepota. São Paulo: Panda Books.

LAJOLO, Marisa; ZILBERMAN, Regina (2007). Literatura infantil brasileira: história e histórias. São Paulo: Editora Ática.

MINAPOTY, Lia (2015). Lua menina e menino onça. Belo Horizonte: RHJ. MUNDURUKU, Daniel (2012). O caráter educativo do movimento indígena brasileiro (1970 -1990). São Paulo: Paulinas.

(2016). Memórias de índio: uma quase autobiografia. Porto Alegre: Eldebra.

OITTINEN, Riitta (2000). Translating for children. Taylor \& Francis e-library. ROSE, Jacqueline S. (1998). "The case of Peter Pan". In: JENKINS, Henry (Ed.). The children's culture reader. Nova lorque: NY Press.

YAMÃ, Yaguarê (2012). Contos da floresta. São Paulo: Petrópolis.

Lívia Penedo Jacob é Doutora em Teoria da Literatura e Literatura Comparada pela UERJ (2016-2020) com apoio da CAPES. Pesquisou sobre literatura indígena contemporânea, pós-colonialismo e alteridade junto à Universidade de Winnipeg (Canadá). Mestre em Linguística pela PUC-Rio com apoio financeiro do CNPq (2008-2010), tendo pesquisado formação de palavras e teoria lexical. Foi professora de Português da rede municipal da cidade do Rio de Janeiro em 2010. Concursada, atuou como Assistente Executiva junto à Secretaria de Educação do Estado do Rio de Janeiro (2013-2014). Foi também concursada da 
Fundação CEDERJ-CECIERJ (2014-2018), onde atuou na área de projetos educacionais. Suas publicações mais recentes são: "Carta Branca: Embates entre a voz emergente e a escrita circunscrita" (2018); "O sonho de Gregor Samsa" (2017); "Alteridades às margens dos antepassados: figurações indígenas em quatro obras contemporâneas" (2017). ORCID iD: https://orcid.org/0000-0002-4863-1210

Recebido em 02 de fevereiro de 2020. Aprovado em 15 de julho de 2020. 